BMJ Open

Diabetes

Research

\& Care

\section{Discovering successful strategies for diabetic self-management: a qualitative comparative study}

\author{
Susan C Weller, ${ }^{1,2}$ Roberta Baer, ${ }^{3}$ Anita Nash, ${ }^{4}$ Noe Perez ${ }^{4}$
}

To cite: Weller SC, Baer R, Nash A, et al. Discovering successful strategies for diabetic self-management: a qualitative comparative study. BMJ Open Diab Res Care 2017;5:e000349. doi:10.1136/ bmjdrc-2016-000349

Received 25 0ctober 2016 Revised 3 February 2017 Accepted 14 March 2017
CrossMark

\begin{abstract}
${ }^{1}$ Department of Family Medicine, University of Texas Medical Branch, Galveston, Texas, USA

${ }^{2}$ Department of Family Medicine, University of Texas Medical Branch, Galveston, Texas, USA

${ }^{3}$ Department of Anthropology, University of South Florida, Tampa, Florida, USA ${ }^{4}$ Department of Preventive Medicine and Community Health, University of Texas Medical Branch, Galveston, Texas, USA
\end{abstract}

Correspondence to Dr Susan C Weller; sweller@utmb.edu

\section{ABSTRACT}

Objective This project explored lifestyles of patients in good and poor control to identify naturally occurring practices and strategies that result in successful diabetes management.

\section{Research design and methods Semistructured}

interviews with adult patients with type 2 diabetes explored diet, food preparation, physical activity, medication use and glucose monitoring. Patients $(n=56)$ were classified into good (A1C $<7.0 \%)$, fair $(7.0 \% \leq \mathrm{A} 1 \mathrm{C}<8.0 \%)$ or poor (A1C $>8.0 \%$ ) control groups and matched across groups on diabetes duration ( \pm 5 years) and medication modality (none, oral, insulin \pm oral) to control for non-lifestyle factors. A qualitative comparative analysis identified practices that distinguished glycemic groups.

Results Good control patients were more likely to test their glucose two or more times a day and reduce their sodium intake, as well as increase fruits and vegetables and limit portion sizes, some attaining good control without exercise. Fair control patients discussed several dietary strategies including limiting sweets, drinking non-caloric beverages, reducing carbs, 'cheating' (eating only a few sweets/limiting carbs in one meal to have more in another meal) and tested their glucose once a day. Poor control patients were more likely to skip antidiabetic medications and not test their glucose.

Conclusions Although clinical trials indicate most self-management practices have limited effectiveness over time, increased glucose monitoring is a valuable component in daily management. Research is needed on effectiveness of dietary strategies that emphasize sodium monitoring and allow some degree of cheating. Reoffering diabetes education classes and providing pill boxes as memory aids may help improve poor control.

\section{INTRODUCTION}

Diabetes is a leading cause of new cases of blindness, kidney failure and non-traumatic amputations. Tighter glycemic control is associated with better long-term outcomes and fewer complications, ${ }^{1}$ but only about half $(52.5 \%)$ of patients with diabetes in the USA are in good control $(\mathrm{A} 1 \mathrm{C}<7.0 \%){ }^{2}$ Most cases are type 2 diabetes mellitus and are managed with diet, exercise, and usually medications. Self-care/self-management is an essential part of diabetes management and includes patient practices concerning diet, physical activity,

\section{Significance of this study}

What is already known about this subject? Self-management practices (medication use, selfmonitoring of blood glucose (SMBG), exercise and so on) are efficacious in clinical trials, but half of patients with diabetes have not attained good glycemic control.

What are the new findings?

Results suggest good control can be attained with attention to diet and SMBG without exercise.

How might these results change the focus of research or clinical practice?

Results suggest research is needed on effectiveness of dietary strategies (monitoring sodium and cheating) and use of pill boxes for improving glycemic control.

glucose monitoring, and correct medication use. This project compares daily self-management practices of good and poor control patients in order to identify successful strategies for attaining glycemic control.

Clinical trials demonstrate that medications reduce glycemia and that lowered glycemia can prevent or delay development of complications, especially in newly diagnosed patients. ${ }^{1}$ Even improvement from very poor control to fair control can reduce complications. ${ }^{3}$ However, medication effectiveness is diminished by lack of adherence, and longer disease duration increases glycemia, requiring more or different medications over time. ${ }^{2}$ Self-monitoring of blood glucose (SMBG) may make small or temporary A1C improvements. ${ }^{4}$ Exercise also may improve A1C with or without weight loss. ${ }^{5}$ Depression complicates self-management, hyperglycemia increases the risk of depression, ${ }^{6}$ and patients with depression are less adherent. ${ }^{7}$ Since about half of US patients with diabetes are in fair or poor control $(\mathrm{A} 1 \mathrm{C}>7.0)$ and about a quarter of all patients with diabetes are in poor control $(\mathrm{A} 1 \mathrm{C}>8.0),{ }^{2}$ we need better information on patient understanding and practices concerning medications, glucose 
monitoring, exercise, and diet to develop more successful strategies for patient-centered care.

National surveys, based on representative samples, are important sources of information, but are limited in the depth and breadth of questions asked. Similarly, studies using standardized scales and questionnaires cannot explore personal practices in depth. In contrast, qualitative studies can explore issues in depth, although small non-representative samples may limit generalizability. A strength of qualitative studies is their ability to explore and identify new variables and patterns. In-depth interviews comparing self-management practices of good and poor control patients can help to identify successful management strategies. New variables and ideas can then be included and verified in further studies. However, few qualitative studies have compared type 2 diabetes management practices across glycemic control groups. ${ }^{8-10}$

This study takes a patient-centered approach and uses qualitative interviewing to explore everyday practices, outside of controlled trials, to discover whether those in good control have distinctive practices that might help others attain good control. Thus, this study describes and compares practices reported by patients in good, fair, and poor control to identify successful strategies associated with better glycemic control in patients with type 2 diabetes.

\section{RESEARCH DESIGN AND IMETHODS}

To identify self-management practices that distinguish different levels of glycemic control, in-depth interviews were combined with a comparative study design. Single group studies that do not contrast patients by control status cannot differentiate factors that distinguish good and poor control patients; it is only by separating and comparing glycemic control groups that distinguishing behaviors can be identified. A matched design was used to minimize the effect of confounding variables. ${ }^{11}$ Each good control case was matched to a fair and a poor control patient on variables associated with glycemic control, but that are not under direct patient control (duration of disease and medication modality). For example, because insulin use is associated with higher A1C levels and insulin use is also associated with glucose testing, a higher proportion of insulin users in the poor control group would confound and bias a comparison of self-management comparisons across groups. Diabetes duration and medication modality must be distributed similarly in the glycemic control subgroups, so that differences between the groups will reflect self-management practices and not physiologic correlates of disease. By controlling for these variables to the extent possible, differences between groups due to the effects of duration of disease and medication modality are minimized and lifestyle differences are highlighted. Finally, qualitative interviewing techniques from anthropology were used to explore individual variations in living with diabetes. ${ }^{12}{ }^{13}$ Open-ended questions explored topics relevant to diabetes management with probing for detail and examples, to elicit exhaustive, detailed responses. Thus, this study uses a comparative design with qualitative outcome variables to elicit patient strategies for managing their diabetes and identify strategies related to glycemic control.

\section{Participants}

Adult patients ( $\geq 18$ years of age) with type 2 diabetes for at least 1 year were interviewed in university-affiliated Family Medicine Clinics in Galveston, Texas (2010 population 48440). The patient population is ethnically diverse: $62 \%$ white, $17 \%$ Hispanic, and 17\% African-American. Patients were recruited from clinical waiting areas, the study purpose explained, and informed consent obtained for the interview and for obtaining A1C laboratory results from their medical records. The Institutional Review Board approved this study.

\section{Procedure}

Participants were asked open-ended questions about lifestyle factors that affect glycemic control (medication use, diet, exercise, glucose testing, support, and so on), their disease history (duration and medications), and demographic information (age, gender, and ethnicity). Free-listing interviews were conducted, where lists of responses were collected from each participant for each question. ${ }^{12}$ Open-ended questions were asked, and probes were used to obtain more information and multiple responses to elicit an exhaustive list of answers from each individual for each question. Free-listing collects more information per individual, so that saturation (the point at which little or no new information is obtained) is achieved with smaller samples. Framing the necessary sample size in terms of the likelihood of capturing important ideas, a sample size of at least 15 per group would have a $90 \%$ probability for capturing ideas held by $25 \%$ of the population. ${ }^{14}$

\section{Analysis}

First, ideas or themes mentioned in response to openended questions were independently coded and verified by two people. The set of thematic codes was developed iteratively; an initial list based on the first few interviews was revised as subsequent interviews were coded. The final set of codes was developed on the first 30 interviews, and all interviews were coded with those codes. Free-listing facilitated coding as ideas tended to appear as new items on individual lists. Interviews were reviewed and coded by the interviewer (NP or AN) to identify themes and ideas, and then each interview was independently coded by a second person (SCW). Disagreements between coders were few and were easily reconciled, as they typically occurred because a theme was mentioned at some time during the interview, but not necessarily in response to a specific question.

Second, A1C was obtained from patient medical records after interviews and coding were complete, so that interviewers and coders were blinded to (and could not be 
biased by) the patients' glycemic control status. Since patients should have an A1C at least every 6 months, ${ }^{15}$ $\mathrm{A} 1 \mathrm{C}$ values were considered valid if they were within 6 months of the date of interview. A1C values closest to the interview date were used. Patients were divided into three groups: good (A1C $<7.0 \%(53 \mathrm{mmol} / \mathrm{mol}))$, fair $(7.0 \%(53 \mathrm{mmol} / \mathrm{mol}) \leq \mathrm{A} 1 \mathrm{C}<8.0 \%(65 \mathrm{mmol} / \mathrm{mol}))$, or poor $(\mathrm{A} 1 \mathrm{C}>8.0 \%(65 \mathrm{mmol} / \mathrm{mol}))$ and matched across groups on medication modality (none, oral, or insulin with or without oral medications) and duration of disease $( \pm 5$ years) to ensure that medications and diabetes duration were distributed similarly within each of the glycemic control groups.

Third, the relative salience of ideas and themes was estimated for each of the three glycemic control groups. A spreadsheet was created with columns for the thematic codes, rows for people, and entries indicating whether each person mentioned a code $(0=$ no and $1=y e s)$. The relative importance or salience of themes could then be estimated with the percentage of respondents in each group that mentioned each theme. ${ }^{16}$ Themes mentioned by more people were assumed to be more salient than themes mentioned by few people. Since the purpose was to identify themes that distinguished the groups, themes with approximately $20 \%$ difference between groups were identified as possibly meaningful.

Finally, a qualitative comparative analysis (QCA) was conducted to identify key themes linked to better glycemic control. ${ }^{16-20}$ QCA uses formal Boolean logic to identify distinguishing factors ('prime implicants') ${ }^{16}$ between subgroups by comparing the presence or absence of codes across cases. QCA considers all possible combinations of codes, whether those combinations do or do not occur, and consistencies within and between groups to identify logical relationships linking thematic codes to group membership.

\section{RESULTS}

Interviews ranged from 15 to $30 \mathrm{~min}$ and were conducted in waiting areas and exam rooms, before and after medical appointments. Although there were 62 completed interviews, only 56 were used in this analysis. Two were excluded because of out-of-date A1C information and four could not be matched. Most (90\%) A1C values were within 4 months of the interview date. Mean A1C was $7.8( \pm 2.1)$. Because matching did not take place until all interviews were completed and coded, some cases could not be completely matched: 42 patients were completely matched across the three categories, 14 were matched across only two categories, and 4 (2 good and 2 poor control) were excluded because they could not be matched. Thus, the final sample retained 56 interviews: 20 patients in good control, 16 in fair control, and 20 in poor control. Medication modality and duration of disease were distributed similarly in each group (table 1). Group sample sizes were adequate to capture meaningful population themes and ideas. The majority of

\begin{tabular}{llll}
\hline Table 1 Sample description & & & \\
\hline Variable & Good & Fair & Poor \\
\hline Age (years) & 64.9 & 64.4 & 56.8 \\
\hline Gender (female) (\%) & 75 & 60 & 61 \\
\hline Antidiabetic medications (\%) & & & \\
$\quad$ None & 15 & 13 & 10 \\
\hline Oral & 65 & 63 & 65 \\
\hline Insulin \pm oral & 20 & 25 & 25 \\
\hline Duration (\%) & & & \\
$\quad<5$ years & 50 & 50 & 50 \\
\hline 6-10years & 25 & 25 & 25 \\
\hline $11-15$ years & 10 & 13 & 10 \\
\hline 16+ years & 15 & 13 & 20 \\
\hline Ethnicity (\%) & & & \\
$\quad$ White & 42 & 27 & 44 \\
\hline African-American & 37 & 27 & 22 \\
\hline Mexican/Hispanic & 21 & 47 & 28 \\
\hline Other & 0 & 7 & 6 \\
\hline
\end{tabular}

respondents were older (mean age 62 years) and female $(65 \%)$. The sample included non-Hispanic whites (38\%), African-Americans (29\%), and Hispanics (29\%).

\section{Medication adherence}

Patients were asked about medications they take for diabetes, how much they take, how often, and how they took these medications in the last 3 months. Later in the interview they were asked if they did anything special to manage their diabetes and asked again about medications. Issues in adherence were evident as patients reported reducing their medications, usually due to forgetting. Some said they took their medications 'about one every two days', 'two times a week on average', 'often miss sometimes one dose but sometimes both doses', and 'two to three times a week I forget'. A few stopped medications altogether, 'stopped for the last 6 months, but restarted 3 weeks ago' and one 'stopped 3 months ago', went to Mexico for treatment and is now on a tea regimen, aloe vera, and has restarted medications. One patient reduced a twice daily dose to once daily and another misunderstood administration of oral medication and did not take medications with meals ('two times a day, every 12 hours'). Patients who did not take their medication as prescribed were much more likely to be in poor control (table 2). A third of patients in poor control did not take their medications as instructed compared with only one person in good control (5\%) and one person in fair control (6\%). Medication errors and omissions occurred primarily with oral medications; almost half of those in poor control who took oral medications did not take their medications as prescribed. In contrast, patients in good control were more likely to report memory aids to help remember medications. Some linked their pill taking to an activity 


\begin{tabular}{|c|c|c|c|}
\hline & Good (\%) & Fair (\%) & Poor (\%) \\
\hline $\begin{array}{l}\text { Reduced/skipped } \\
\text { medication }\end{array}$ & 5 & 6 & 33 \\
\hline Pill box as memory aid & 20 & 0 & 10 \\
\hline \multicolumn{4}{|l|}{$\begin{array}{l}\text { Glucose monitoring } \\
\text { frequency }\end{array}$} \\
\hline No/never & 0 & 13 & 22 \\
\hline Some & 26 & 13 & 28 \\
\hline Once a day & 26 & 40 & 17 \\
\hline $2 x+/$ day & 47 & 33 & 33 \\
\hline Define A1C? & 32 & 33 & 33 \\
\hline
\end{tabular}

(when I go to work, when I get up in the morning, or with meals), but the most frequently reported memory aid was the use of a weekly pillbox organizer.

\section{Glucose monitoring}

Although A1C is the standard for assessing glycemic control, only a third of patients understood the term (table 2). Patients who reported that A1C was a measure of 'average blood sugar' or if they did not know, but could offer a range when it was considered to be 'good', were coded as understanding the term. When asked about SMBG and then their testing in the past 3 months, four patients reported testing less frequently in the past 3 months. Most patients reported at least some SMBG, but $22 \%$ of those in poor control reported that they never tested their blood sugar. Patients who reported testing two or more times a day tended to be in good control, those who tested once a day were more likely to be in fair control, and those who tested 'sometimes' or 'never' were more likely to be in poor control (table 2). All but one patient using insulin tested at least once a day. Of the non-insulin users, $94 \%$ of those in good control, $63 \%$ in fair control, and $50 \%$ of those in poor control reported SMBG.

\section{Dietary themes}

Patients were asked to describe their diet, meal preparation, and dietary eating strategies, and whether their diet changed since becoming a diabetic. Responses represent spontaneously mentioned comments to those general questions (table 3). There was a striking difference between groups in the monitoring of salt intake. Those in good control were much more likely than those in fair or poor control to report limiting salt in their diet, and those in fair control were more likely to report salt reduction than were those in poor control $(53 \%$ good, $27 \%$ fair, and $6 \%$ poor). Those in good or fair control were more likley to report increasing their fruit and vegetable consumption and using portion/calorie control. Those in fair control were more likely to say that they changed their diet for diabetes and to report 'cheating' behaviors (47\% fair vs $11 \%$ good and $17 \%$ poor), such as: 'every now and

\begin{tabular}{|c|c|c|c|}
\hline & Good (\%) & Fair (\%) & Poor (\%) \\
\hline Sugar reduction (general) & 47 & 80 & 61 \\
\hline $\begin{array}{l}\text { Sugar substitution } \\
\text { (specific) }\end{array}$ & 21 & 20 & 28 \\
\hline Cheating behaviors & 11 & 47 & 17 \\
\hline Sweetener in drinks & 32 & 33 & 17 \\
\hline $\begin{array}{l}\text { Diet drinks/no sugared } \\
\text { sodas }\end{array}$ & 26 & 47 & 39 \\
\hline Starch/carb reduction & 42 & 60 & 33 \\
\hline $\begin{array}{l}\text { Increased intake of fruits } \\
\text { and vegetables }\end{array}$ & 47 & 40 & 28 \\
\hline $\begin{array}{l}\text { Specified amount non- } \\
\text { starch vegetables }\end{array}$ & 11 & 13 & 17 \\
\hline Fruit as a snack & 21 & 33 & 22 \\
\hline Lean cooking methods & 21 & 27 & 22 \\
\hline Fat reduction & 16 & 13 & 11 \\
\hline $\begin{array}{l}\text { Lean meat (fish, chicken, } \\
\text { less meat) }\end{array}$ & 21 & 27 & 11 \\
\hline Limit or no alcohol & 11 & 27 & 11 \\
\hline Salt reduction & 53 & 27 & 6 \\
\hline $\begin{array}{l}\text { Portion control/calorie } \\
\text { count }\end{array}$ & 32 & 13 & 28 \\
\hline Strategies for eating out & 5 & 13 & 0 \\
\hline Regularly scheduled meals & 20 & 38 & 20 \\
\hline Two meals & 11 & 7 & 6 \\
\hline Three meals & 0 & 20 & 6 \\
\hline Changed diet for DM & 42 & 67 & 44 \\
\hline
\end{tabular}

DM, diabetes mellitus.

then, I eat... (ice cream, a candy bar)', 'Every so often, I'm bad and have some birthday cake', or 'I only have a small piece of candy'. Many patients described avoiding sugary or sweet foods, but those in fair control were much more likely to report reducing sweets ('I eat less sweets' and 'I eat food low in sugar'), reducing starches/carbohydrates, and eliminating sugared sodas from their diet.

\section{Physical activity}

There was a high overall rate of disabilities (back injuries, problems with knees and feet, walks with a cane or walker, vision problems, and so on) and/or comorbidities (previous myocardial infarction or stroke) that limit activities (table 4). Often, these injuries limited exercise, 'I used to walk twice a day for about $15 \mathrm{~min}$, but I broke my foot and haven't walked as much since'. Disabilities, however, were fairly equally distributed across the three glycemic groups. Many described their activity as 'walking around in my house'. The rate of activity and focused exercise was about the same across the three groups except that more people in good control reported no physical activity. 


\begin{tabular}{|c|c|c|c|}
\hline & Good (\%) & Fair (\%) & Poor (\%) \\
\hline Disabilities & 55 & 50 & 45 \\
\hline \multicolumn{4}{|l|}{ Activity } \\
\hline None & 21 & 7 & 6 \\
\hline In home & 32 & 40 & 44 \\
\hline Some exercise & 32 & 27 & 28 \\
\hline 20-30 m 3x/week & 16 & 27 & 22 \\
\hline $\begin{array}{l}\text { Changed exercise } \\
\text { for DM }\end{array}$ & 15 & 13 & 5 \\
\hline
\end{tabular}

DM, diabetes mellitus.

\section{Diabetes education}

Almost two-thirds (62\%) of patients reported taking a diabetes education class. Most comments about those classes focused on food and diet, for example, 'They talked about what to eat' and 'portion size' (table 5). Fewer in fair control reported learning about diet and instead reported learning how to test their glucose. However, more of those in poor control reported taking an education class 'when they were first diagnosed' or 'a long time ago' $(46 \%)$.

\section{Social support}

When asked how family and friends help you manage your diabetes, few patients reported a meaningful amount of support (table 5). In fact, there was a tendency for those in better and fair control to report less support than those in poor control: $60 \%$ of those in good control, $53 \%$ of those in fair control, and $40 \%$ of those in poor control reported no support.

\section{Key themes linked to glycemic control}

QCA results identified key themes and combinations of themes linked to gylcemic control. QCA suggested a single path to good control (distinguishing good control from the combined group of fair and poor control patients) with SMBG (none vs any), monitoring of sodium intake,

\begin{tabular}{|c|c|c|c|}
\hline & Good (\%) & Fair (\%) & Poor (\%) \\
\hline \multicolumn{4}{|l|}{ Educational content } \\
\hline $\begin{array}{l}\text { What to eat (diet), } \\
\text { portions }\end{array}$ & 62 & 38 & 62 \\
\hline How to test glucose & 15 & 38 & 15 \\
\hline Exercise & 8 & 13 & 0 \\
\hline Not useful & 23 & 13 & 15 \\
\hline When first diagnosed & 23 & 25 & 46 \\
\hline \multicolumn{4}{|l|}{ Social support } \\
\hline None & 60 & 53 & 40 \\
\hline Some & 40 & 40 & 55 \\
\hline Daily/a lot & 5 & 7 & 5 \\
\hline
\end{tabular}

and no dietary cheating. Good control patients were further distinguished from fair control patients by SMBG, no dietary cheating, and not having changed their diet for diabetes.

Poor control patients were distinguished from fair and good control patients by skipping medications and not monitoring sodium. One subgroup of poor control patients skipped medications, did not monitor sodium, and had a diabetes education class 'a long time ago'. Another subgroup of poor control patients tested their glucose but skipped medications and did not monitor sodium. Poor and fair control patients were further distinguished by sodium monitoring, pill box use, and dietary cheating strategies. QCA suggested two paths from poor to fair control. One path was with sodium monitoring, pill box use, and no dietary cheating. A second path was with sodium monitoring, no pill box use, and dietary cheating.

\section{CONCLUSIONS}

This study attempted to identify successful lifestyle strategies for the management of type 2 diabetes. While specific self-management practices have been shown to be efficacious in clinical trials (medication use, SMBG, exercise, and so on), their effectiveness wanes over time. Typically patients have been exposed to management practices during diabetes education classes and clinic visits, but it is unclear to what degree these practices have been incorporated into everyday life.

Qualitative, open-ended interviews were used to explore how patients with type 2 diabetes managed their diabetes and specifically to see if patients in good and poor control had distinctive practices. The contrast of good and poor control groups, while controlling for duration and medication, facilitated identification of lifestyle practices while controlling for factors that are less under patient control. Few qualitative studies have explored diabetes management issues with reference to patients' glycemic control. Hunt et $a l^{8}$ found similar themes but no differences between groups in management practices, and Savoca $e t$ $a l^{\vartheta}$ found good control patients coped better with their diagnosis and 'persevered' with their diets. O'Connor et al found those with greater reductions in A1C had integrated dietary choices and testing into their daily lives, ${ }^{10}$ Scholes $e t$ $a l^{21}$ compared good and poor control adolescent patients with type 1 diabetes and found greater parental involvement with care and meal preparation in those in better control. In studies of type 2 diabetes, however, the design must also control for duration of disease and medication modality to minimize bias caused by having more patients with a shorter duration of disease in the good control group and by having patients with a longer duration of disease and more insulin use in the poor control group. The unequal distribution of these factors in the groups confounds comparisons of management practices. Only de Alba Garcia et al used such a design in a qualitative comparative study in Mexico and found distinctive themes and practices similar to those identified in this study. ${ }^{22}$ 
In our study, few self-management practices distinguished good control from fair and poor control patients. The first was SMBG. Patients in good control tested their glucose at least twice a day. Although meta-analyses of clinical trials show that SMBG has a small effect over time, ${ }^{4}$ our results suggest that those who incorporated testing into their daily routines and those who tested more often were in better control. SMBG may help patients to understand the direct link between what they eat and their blood sugar ${ }^{23}$ but may also indicate overall motivation. A second practice concerned limiting dietary salt/sodium. Although there is no mechanism linking sodium intake with glycemia, monitoring of dietary sodium may indicate dietary vigilance, with attention paid to food content and composition, and reading of nutritional food labels and limiting prepared foods. Extreme levels of dietary sodium are associated with increased mortality. ${ }^{24}{ }^{25}$ Education on reading and using nutritional labels when shopping, with actual shopping experience, may be part of a more effective diabetes education experience. ${ }^{26}$ Both SMBG and sodium reduction point to an overall vigilance and active participation in management concerning food, its content, and resulting blood sugar levels. Good control patients tended not to cheat and increased fruits and vegetables, decreased portion sizes, and often attaining good control without exercising. They also reported not changing their diet: one good control patient remarked, she did not 'consistently do stuff for diabetes', but tried 'to stay as normal as possible'.

Patients in poor control tended to skip medications and not monitor sodium. While non-adherence is associated with poorer control, it is often linked to cost or complexity in dosing ${ }^{27}$ and not necessarily to simple forgetting, although the rate of forgetting may be high among those in poor control. ${ }^{28}$ Patients may purposefully reduce their dosage, but many may simply forget or misunderstand dosages. Helping patients take medications correctly includes asking how they currently take their medications, explaining key information, and describing daily reminder options. ${ }^{29}$ Pill boxes tended to be used by those in good control to remember their medications and these might be offered to all patients to remember their pills. Poor control patients also might benefit most from diabetes education classes. ${ }^{30}$ Diabetes education is an ongoing process to facilitate self-care; reassessments and referrals can occur at diagnosis, but also during annual evaluations of needs and transitions in care or with the development of complications. ${ }^{31}$ Also, since many patients were unclear on what A1C was, point-of-care testing with direct rather than delayed feedback might facilitate better understanding of the A1C measure. ${ }^{32}$ Incorporation of SMBG may help patients link dietary intake with blood glucose, providing valuable feedback for patients who do not normally monitor their blood glucose. ${ }^{23}$

Patients in fair control described more elaborate dietary strategies for diabetes management than either good or poor control groups. Patients in fair control talked about having changed their diet because of diabetes. QCA results suggested an interplay between the themes of monitoring dietary sodium and making dietary changes. Those in fair or poor control were more likely to report that they changed their diet in general for diabetes, while those in better control tended to report specifically that they monitored their sodium intake. Those in fair control also described cheating behaviors, eating only a little candy/ cake or limiting carbs all day in anticipation of a heavy carb night-time meal. A limitation of interviews done at only one point in time, however, is that it is impossible to see if these strategies have successfully moved these patients from poor to fair control, or if these strategies have kept these patients from being in good control. This group appears to spend more effort negotiating dietary issues and only tests their glucose once a day. While the glycemic index of foods ${ }^{33}$ may affect A1C, patients might be encouraged to test two times a day to learn whether their dietary strategies are working.

Dietary strategies have been discovered in other qualitative studies comparing good and poor control patients. A study in Mexico found good control patients were more likely to eat only two meals a day (with fruit snacks), use beverages (coffee and tea) to satisfy desires for more food, and to admit eating forbidden foods. ${ }^{22}$ An intervention study found that patients who improved their A1C reported more dietary cheating behaviors. ${ }^{10}$ Positive responders took their diagnosis more seriously with the onset of diabetes complications and learned the importance of diet and how to 'cheat' on it, incorporating adjustments (glucose testing and taking medications) into their daily life. These findings suggest that flexibility in dietary choices combined with SMBG may be helpful in eating more 'normally'.

Exercise notably did not distinguish good control from fair or poor control groups. Few patients exercised, and there was a high rate of physical disabilities limiting physical activity. Although research suggests that exercise may improve A1C, ${ }^{34}$ patients may be unlikely to add exercise to their daily schedules. Here, it was the lack of exercise that distinguished the good control group, suggesting that good control may be attained without a regular exercise program or with minimal exercise. This supports recent findings that even activity in and around the house is beneficial. ${ }^{3 .}$

An additional finding was related to patient-provider communication. Specifically, more accurate information can be obtained from patients when questions are posed in pairs: a general question followed by a more specific question on the same topic. Following a general question with a question about behavior for a specific time period (in the past 3 months) sometimes changed responses. The general question is more sensitive to social desirability bias, while the follow-up question elicits more accurate information about behaviors. This pattern follows the experience in survey research, ${ }^{36}$ where a series of questions are recommended to emphasize the importance of the information and also improves accuracy. For example, 
What medications do you take for your diabetes? How do you take these medicines? How have you taken these in the past 3 months? Or, since you had diabetes have you tested your blood sugar? Do you usually test it? In the past 3 months have you tested your blood sugar? Questions about physical activity also had to probe about activities in and around the home and focused exercise (with duration and frequency). It was through such multiple questions that patients readily volunteered differences between prescribed and actual doses of medications and variation in glucose testing.

Patient-centered concerns identified in this study contrast with concerns of healthcare providers. A systematic review of qualitative studies of doctors and nurses concluded that uncertainties about management guidelines, outcomes, and initiation of insulin are barriers to effective management of type 2 diabetes. ${ }^{37}$ Here, patients identified themes that re-enforced the importance of diabetes educational content, such as glucose monitoring and medication adherence, and identified dietary themes that may need greater emphasis, such as reducing dietary salt. Nutritional education must address the reality of patients' lives and develop flexible strategies to manage diet on a long-term basis, possibly hand-in-hand with SMBG. Identification of successful strategies for diabetes management can help improve diabetes education and physician-patient communication. Emphasizing successful management strategies that have been developed by patients themselves and reflect the actual reality of the daily challenges of living with diabetes may help other patients and improve their ability to manage their disease. This study identified dietary, educational, and self-management strategies as possible mechanisms for attaining better glycemic control in the daily lives of diabetic patients. Future research needs to systematically explore and test the effectiveness of these strategies.

Contributors SCW designed the study, participated in interviewing, coding, analysis and writing the manuscript; and is the guarantor. RB assisted in designing the study, interpreting data and writing the manuscript. AN participated in interviewing, coding, interpreting data and preparing the manuscript. NP participated in interviewing, coding, interpreting data and preparing the manuscript.

Funding This study was funded by the US National ScienceFoundation (BCS0108232, BCS -0108228) and by the University of Texas MedicalBranch Department of Family Medicine.

Competing interests None declared.

Patient consent All participating patients signed a consent form approved by the University Institutional Review Board. No personally identifiable information or photos included in the manuscript.

Ethics approval University of Texas Medical Branch Institutional Review Board. Provenance and peer review Not commissioned; externally peer reviewed.

Data sharing statement Original dichotomous coded data are available from the authors (SCW) upon request.

Open Access This is an Open Access article distributed in accordance with the Creative Commons Attribution Non Commercial (CC BY-NC 4.0) license, which permits others to distribute, remix, adapt, build upon this work non-commercially, and license their derivative works on different terms, provided the original work is properly cited and the use is non-commercial. See: http://creativecommons.org/ licenses/by-nc/4.0/ (c) Article author(s) (or their employer(s) unless otherwise stated in the text of the article) 2017. All rights reserved. No commercial use is permitted unless otherwise expressly granted.

\section{REFERENCES}

1. UK Prospective Diabetes Study (UKPDS) Group. Intensive bloodglucose control with sulphonylureas or insulin compared with conventional treatment and risk of complications in patients with type 2 diabetes (UKPDS 33). Lancet 1998;352:837-53.

2. Casagrande SS, Fradkin JE, Saydah SH, et al. The prevalence of meeting $\mathrm{A} 1 \mathrm{C}$, blood pressure, and LDL goals among people with diabetes1988-2010. Diab Care 2013;36:2271-9.

3. Adler Al, Stratton IM, Neil HA, et al. Association of systolic blood pressure with macrovascular and microvascular complications of type 2 diabetes (UKPDS 36): prospective observational study. BMJ 2000;321:412-9.

4. Malanda UL, Welschen LM, Riphagen II, et al. Self-monitoring of blood glucose in patients with type 2 diabetes mellitus who are not using insulin. Cochrane Database Syst Rev 2012;1:CD005060.

5. Thomas D, Elliot EJ, Naughton GA. Exercise for type 2 diabetes mellitus. Cochrane Database Syst Rev 2006.

6. Lustman PJ, Anderson RJ, Freedland KE, et al. Depression and poor glycemic control: a meta-analytic review of the literature. Diabetes Care 2000;23:934-42.

7. Gonzales JS, Safren SA, Cagliero E, et al. Depression, self-care, and medication adherence in type 2 diabetes. Diab Care 2007;30:2222-7.

8. Hunt LM, Valenzuela MA, Pugh JA. Porque me tocó a mi? Mexican American diabetes patients' causal stories and their relationship to treatment behaviors. Soc Sci Med 1998;46:959-69.

9. Savoca M, Miller C, Quandt S. Profiles of people with type 2 diabetes mellitus. Soc Sci Med 2004;58:2655-66.

10. O'Connor PJ, Crabtree BF, Yanoshik MK. Differences between diabetic patients who do and do not respond to a diabetes care intervention: a qualitative analysis. Fam Med 1997;29:424-8.

11. Schlesselman JJ. Case-control studies: design, conduct, analysis. New York: Oxford University Press, 1982.

12. Weller SC, Romney AK, et al. Systematic data collection, sage qualitative methods. Newbury Park, CA: Sage Publications, 1988;10.

13. Weller SC, Baer RD, Garcia de Alba Garcia J, et al. Explanatory models of diabetes in the US and Mexico: the patient-provider gap and cultural competence. Soc Sci Med 2012;75:1088-96.

14. Fugard AJB, Potts HWW. Supporting thinking on sample sizes for thematic analyses: a quantitative tool. Int J Soc Res Methodol 2015;18:669-84.

15. American Diabetes Association. Glycemic targets. Diab Care 2016;39:S39-46.

16. Bernard HR, Ryan GW. Analyzing qualitative data: systematic approaches. Thousand Oaks, California: Sage Publications, 2010.

17. Ragin CC, Mayer SE, Drass KA. Assessing Discrimination: a boolean approach. Am Sociol Rev 1984;49:221-34.

18. Rihoux B, De Meur G. Chapter 3: crisp-set qualitative comparative analysis (csQCA). In: Rihoux B, Ragin CC, Eds. Configurational comparative methods: qualitative comparative analysis (QCA) and related techniques. Thousand Oaks, California. Sage Publications, 2009.

19. Grofman B, Schneider CQ. An introduction to Crisp set QCA, with a comparison to Binary Logistic regression. Polit Res $Q$ 2009;62:662-72.

20. Borgatti SP. Truth tables, Anthropac 4. Natick, MA: Analytic Technologies, 1996.

21. Scholes C, Mandleco B, Roper S, et al. A qualitative study of young people's perspectives of living with type 1 diabetes: do perceptions vary by levels of metabolic control? J Adv Nurs 2013;69:1235-47.

22. de Alba Garcia JG, Rocha AL, Lopez I, et al. 'Diabetes is my companion': lifestyle and self-management among good and poor control Mexican diabetic patients. Soc Sci Med 2007;64:2223-35.

23. Hanley J, Fairbrother P, McCloughan L, et al. Qualitative study of telemonitoring of blood glucose and blood pressure in type 2 diabetes. BMJ Open 2015;5:e008896.

24. Ekinci El, Clarke S, Thomas MC, et al. Dietary salt intake and mortality in patients with type 2 diabetes. Diabetes Care 2011;34:703-9.

25. Graudal N, Jürgens G, Baslund B, et al. Compared with usual sodium intake, low- and excessive-sodium diets are associated with increased mortality: a meta-analysis. Am J Hypertens 2014;27:1129-37.

26. Kollannoor-Samuel G, Shebl FM, Segura-Pérez S, et al. Effects of food label use on diet quality and glycemic control among latinos 
with type 2 diabetes in a community health worker-supported intervention. Am J Public Health 2016;106:1059-66.

27. García-Pérez LE, Alvarez M, Dilla T, et al. Adherence to therapies in patients with type 2 diabetes. Diabetes Ther 2013;4:175-94.

28. Odegard PS, Gray SL. Barriers to medication adherence in poorly controlled diabetes mellitus. Diabetes Educ 2008;34:692-7.

29. Lin EHB, Ciechanowski P. Working with patients to enhance medication adherence. Clin Diabetes 2008;26:17-19.

30. Chrvala CA, Sherr D, Lipman RD. Diabetes self-management education for adults with type 2 diabetes mellitus: a systematic review of the effect on glycemic control. Patient Educ Couns 2016;99:926-43.

31. Powers MA, Bardsley J, Cypress M, et al. Diabetes Self-management Education and Support in Type 2 Diabetes: A Joint Position Statement of the American Diabetes Association, the American Association of Diabetes Educators, and the Academy of Nutrition and Dietetics. Diab Care 2015;38:1372-82.
32. Petersen JR, Finley JB, Okorodudu AO, et al. Effect of point-of-care on maintenance of glycemic control as measured by A1C. Diabetes Care 2007;30:713-5.

33. Thomas D, Elliot EJ. Low glycaemic index, or low glycaemic load, diets for diabetes mellitus. Cochrane Database Syst Rev 2009.

34. Snowling NJ, Hopkins WG. Effects of different modes of exercise training on glucose control and risk factors for complications in type 2 diabetic patients: a meta-analysis. Diabetes Care 2006;29:2518-27.

35. Sparling PB, Howard BJ, Dunstan DW, et al. Recommendations for physical activity in older adults. BMJ 2015;350:h100.

36. Fowler FJ. Improving survey questions design and evaluation. Applied social research methods series. Newbury Park, CA: Sage Publications, 1995;38.

37. Rushforth B, McCrorie C, Glidewell L, et al. Barriers to effective management of type 2 diabetes in primary care: qualitative systematic review. Br J Gen Pract 2016;66:e114-27. 